\title{
Effect of Different Body Postures on the Severity of Stuttering in Young Adults with Developmental Stuttering
}

\author{
Abdulaziz Almudhi, ${ }^{1}$ Hamayun Zafar, ${ }^{2,3}$ Shahnawaz Anwer $\mathbb{D}^{3,},{ }^{3,4}$ and Ahmad Alghadir $\mathbb{D}^{3}$ \\ ${ }^{1}$ Department of Medical Rehabilitation Sciences, College of Applied Medical Sciences, King Khalid University, Abha, Saudi Arabia \\ ${ }^{2}$ Department of Rehabilitation Sciences, College of Applied Medical Sciences, King Saud University, Riyadh, Saudi Arabia \\ ${ }^{3}$ Rehabilitation Research Chair, College of Applied Medical Sciences, King Saud University, Riyadh, Saudi Arabia \\ ${ }^{4}$ Department of Building and Real Estate, Hong Kong Polytechnic University, Kowloon, \\ 6 Hong Kong Special Administrative Region, China
}

Correspondence should be addressed to Shahnawaz Anwer; anwer_shahnawazphysio@rediffmail.com

Received 18 September 2018; Revised 11 March 2019; Accepted 22 July 2019; Published 5 August 2019

Academic Editor: Alberto Raggi

Copyright ( 2019 Abdulaziz Almudhi et al. This is an open access article distributed under the Creative Commons Attribution License, which permits unrestricted use, distribution, and reproduction in any medium, provided the original work is properly cited.

\begin{abstract}
Objective. The current study aimed to investigate the effects of body position on the level and severity of stuttering in young adults with developmental stuttering. Methods. A total of 24 subjects (male: 17; female: 7; mean age: $24.9 \pm 6.2$ years) with developmental stuttering participated. The participants were asked to perform oral reading and spontaneous monologue-speaking tasks in different body postures while their speech was recorded. During reading and speaking tasks, the Stuttering Severity Instrument was used to quantify the severity of stuttering. The effects of different body postures on stuttering severity, reading task, and speaking task scores were analyzed. Results. Significant differences in stuttering severity, reading task, and speaking task scores were found for different body postures. Post hoc analyses revealed a significant difference in stuttering severity, reading task, and speaking task scores when subjects were sitting on a chair with no arm support compared to lying down $(p<0.05)$. Similarly, there were significant differences for two sitting positions (sitting on a chair with no arm support vs sitting on a chair with arm support $(\mathrm{p}<0.05)$ ). Conclusions. Body postures or body segment positions that relax and facilitate the muscles of the neck and shoulders may potentially improve speech fluency in young adults with developmental stuttering.
\end{abstract}

\section{Introduction}

Stuttering is a complex communication disorder with affective, behavioral, and cognitive components [1] and psychological and social effects [2]. There is a widespread agreement that between 4 and $5 \%$ of the preadolescent population is stutterers [3-5]. The prevalence of stuttering in the adult population may be less than $1 \%$ [6]. It has been estimated that the prevalence of stuttering in the global population is $1 \%$ at any time $[3,5,7]$.

There are different treatment approaches for children and adults who stutter since strategies that may work well for preschool children may be of little use for adults [8]. Some therapeutic approaches and treatment programs may allow a person with stuttering (PWS) to improve speech fluency and communicate in an effective way [9]. Alternative approaches may instead focus on cognitive, behavioral, or psychological therapy or use prosthetic devices that deliver altered auditory feedback $[10,11]$. Although researchers strive to understand the key factors associated with therapy success, there is limited information about the exact mechanisms underlying stuttering. Therefore, researchers and clinicians can formulate therapy goals based on the psychological differences between PWS and nonstutterers [12]. Long-term treatment studies can also provide insights into treatable and refractory stuttering behaviors [13]. These types of studies can provide a deeper understanding of stuttering $[14,15]$.

Previous studies had suggested that stuttering is fundamentally considered as a speech motor disorder in addition to language, psychological, or other issues causing further progress of fluency disruptions in both children and adults [16-18]. Past studies have investigated the role of proprioceptive feedback to control and coordinate speech movements $[19,20]$. The results of their study demonstrated that the PWS 
showed less efficient use of proprioceptive feedback to control speech-related or nonspeech-related movements [19, 20]. For example, De Nil and Abbs [20] have indicated that PWS showed reduced use of proprioceptive feedback to control a very small amplitude lip, jaw, and tongue movements. Additionally, PWS showed inaccuracy in the movement control compared to nonstuttering individuals [20]. Moreover, the stuttering severity was significantly correlated with the ability to control even a small movement [19]. However, interestingly, patients with mild stuttering showed poorer use of proprioceptive feedback movements control compared to those with moderate or severe stuttering [21]. In addition, more severe stuttering patients showed significantly slower movements compared to mild or moderate stuttering [21]. Thus, they proposed that, when depending on proprioceptive feedback, patients with more severe stuttering are likely to reduce their movements in order to improve performance and accuracy [21].

Although normal and pathological (e.g., stuttering) speech production depends on multiple factors (i.e., physiological, psychological, neurological, genetic, and environmental factors), sensorimotor control of speech is of paramount importance [13]. Proprioceptive feedback plays a vital role in speech production [21]. The previous study has suggested that this feedback helps us to quickly and usually unknowingly compensate articulatory discoordination [22]. Proprioception is also important for temporospatial coordination of fluent articulatory movements [23]. Training of new motor skills requires the availability of fast and accurate proprioceptive function [24]. This afferent feedback information combined smoothly and quickly with efferent motor signals to help movement to achieve desired outcome [24]. Previous studies suggested that even fluent speech in PWS has been often discoordinated, indicating the presence of a more established motor deficit $[25,26]$. It is currently known that body positioning and posture facilitate neck and shoulder muscles [27]. Moreover, the functional relationship between the neck and jaw has been described [28]. Thus, we suggest that any type of body posture or body segment positioning that facilitates or reduces the load on the neck or shoulder muscles has the potential to improve proprioceptive feedback and fluent articulatory movements in PWS. Therefore, the present study aimed to investigate the effects of body position on stuttering severity in young adults with developmental stuttering. We hypothesized that the lying down position followed by sitting on a chair with arms would be the most effective positions for reducing stuttering severity, as these positions provide maximal body relaxation, which improves speech production.

\section{Methods}

2.1. Study Participants. A total of 24 subjects (male: 17; female: 7 ; mean age: $24.9 \pm 6.2$ years) participated in this study. The subjects had attended stuttering clinics prior to the start of this study. Participant inclusion criteria were as follows: (a) history of stuttering onset prior to six years of age [29]; (b) no motor development issues; (c) no concurrent language or speech development issues; (d) not taking medication that potentially affected articulation, depression, phonation, or respiration; (e) no diagnosis of psychiatric or neurological disorders, cranial nerve VII or hearing impairments, or epilepsy; (f) diagnosis of persistent developmental stuttering; and (g) no therapy of any kind during the previous 12-month period. Consultant Speech Language Pathologist with experience of 13 years made the diagnosis of stuttering in the current study.

2.2. Procedure. This study was conducted at King Saud University-Speech Clinics in Riyadh, Saudi Arabia. All subjects participated in therapy sessions. Subject speech samples were collected in an interview room under two conditions: (1) spontaneous speaking and (2) reading task. A camera and tape recorder were used for session recording.

2.2.1. Stuttering Severity Instrument Measurements. The Stuttering Severity Instrument (SSI-4), 4th Edition [30], quantifies disfluency duration, frequency, and physical features in preschool children through adults. The SSI- 4 enables the assessment of behavioral severity levels in readers and nonreaders. Classification of stuttering severity based on the total score and percentile ranks is as follows: very mild (total score, 10-17; percentile rank, 1-11), mild (total score, 18-24; percentile rank, 12-40), moderate (total score, 25-31; percentile rank, 4177), severe (total score, 32-36; percentile rank, 78-95), and very severe (total score, 37-46; percentile rank, 96-99) [30]. Although there are many fluency assessment tools available, the SSI- 4 is highly recommended due to its thoroughness and procedural reliability. A recent study indicated high interrater relative reliability and intrarater absolute reliability of SSI-4 [31]. For our data analysis, SSI-4 total severity, reading task, and speaking task scores were the dependent variables.

2.2.2. Individual Assessment Session Methods. The participants were asked to perform oral reading and spontaneous monologue-speaking tasks in different body positions, which are described in Table 1 . Testing condition order and reading and speaking tasks were randomized to minimize experimenter bias and adaptation effects, respectively. During these tasks, participants were recorded using a Sony IC Recorder (ICD-AX412F). During the speaking task, participants were told to speak for at least four minutes on any subject (e.g., work or leisure). Moreover, each participant was asked to speak approximately 300 words. To ensure clear recording, a 30-40 cm distance was maintained between the recording device and each participant. Each participant was asked to read an Arabic standardized passage. In each task, the average syllables must be 500 .

2.3. Statistical Analysis. Statistical analysis was performed using SPSS 22.0 Software (IBM Inc., Chicago, IL, USA). Descriptive statistics (i.e., mean, standard deviation, and percentages) were reported for stuttering severity, reading task, and speaking task scores in different postural conditions. Normality of data was tested using the Shapiro-Wilk test ( $p>0.05$ ). The effects of different postural conditions on stuttering severity, reading task, and speaking task scores were analyzed using analysis of variance (ANOVA) with 


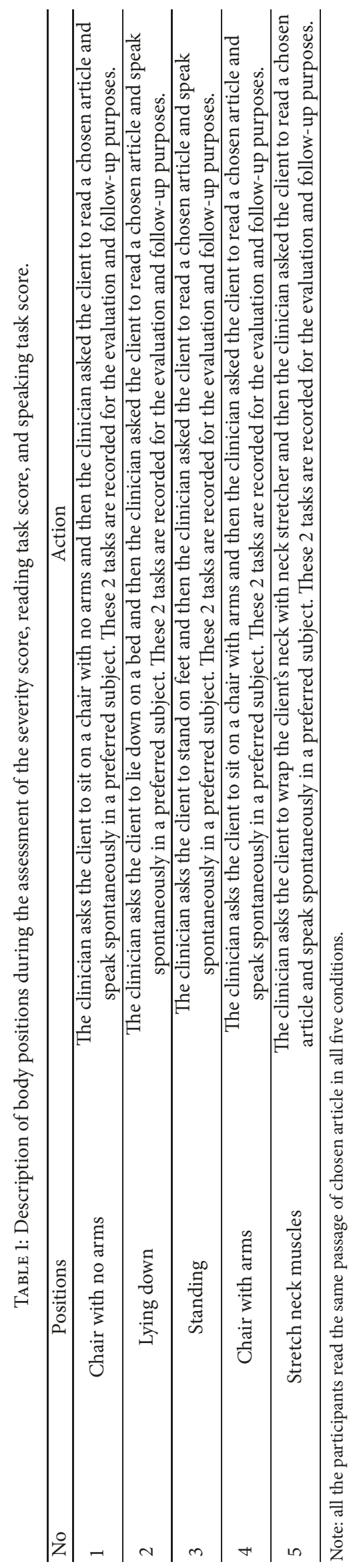


TABLE 2: Descriptive statistics of the severity score, reading task score, and speaking task score in different postural conditions.

\begin{tabular}{|c|c|c|c|}
\hline Group & $\begin{array}{l}\text { Severity score, grading } \\
\text { (\% of the participants) }\end{array}$ & $\begin{array}{l}\text { Reading task score (\% of } \\
\text { the participants) }\end{array}$ & $\begin{array}{c}\text { Speaking task score (\% } \\
\text { of the participants) }\end{array}$ \\
\hline \multirow[t]{7}{*}{ Chair with no arms } & Mild (14.3) & $2(7.1)$ & $3(7.1)$ \\
\hline & Moderate (35.5) & $4(7.1)$ & $7(21.4)$ \\
\hline & Severe (35.6) & $5(14.3)$ & $8(21.4)$ \\
\hline & Very severe (14.6) & $6(42.9)$ & $9(50)$ \\
\hline & & $7(7.1)$ & \\
\hline & & $8(7.1)$ & \\
\hline & & $9(14.3)$ & \\
\hline \multirow[t]{6}{*}{ Lying down } & Mild (64.5) & $2(28.6)$ & $2(7.1)$ \\
\hline & Moderate (35.5) & $4(35.7)$ & $4(14.3)$ \\
\hline & & $5(14.3)$ & $5(7.1)$ \\
\hline & & $6(14.3)$ & $6(42.9)$ \\
\hline & & $7(7.1)$ & $7(21.4)$ \\
\hline & & & $8(7.1)$ \\
\hline \multirow[t]{6}{*}{ Standing } & Mild (28.5) & $2(7.1)$ & $3(7.1)$ \\
\hline & Moderate (49.8) & $4(21.4)$ & $5(7.1)$ \\
\hline & Severe (21.7) & $5(28.6)$ & $6(14.3)$ \\
\hline & & $6(28.6)$ & $7(35.7)$ \\
\hline & & $7(14.3)$ & $8(21.4)$ \\
\hline & & & $9(14.3)$ \\
\hline \multirow[t]{6}{*}{ Chair with arms } & Mild (49.9) & $2(14.2)$ & $2(7.1)$ \\
\hline & Moderate (50.1) & $4(42.9)$ & $4(7.1)$ \\
\hline & & $5(35.8)$ & $5(7.1)$ \\
\hline & & $6(7.1)$ & $6(42.9)$ \\
\hline & & & $7(28.7)$ \\
\hline & & & $8(7.1)$ \\
\hline \multirow[t]{5}{*}{$\begin{array}{l}\text { Stretch neck } \\
\text { muscles }\end{array}$} & Mild (35.6) & $2(7.1)$ & $3(7.1)$ \\
\hline & Moderate (64.4) & $4(28.6)$ & $4(7.1)$ \\
\hline & & $5(50)$ & $6(50)$ \\
\hline & & $6(14.3)$ & $7(21.4)$ \\
\hline & & & $8(14.3)$ \\
\hline
\end{tabular}

repeated measures at a statistical significance level of 0.05 . If interactions of different postural conditions were detected, a post hoc analysis with Bonferroni adjustment was employed.

\section{Results}

3.1. Participant Characteristics. Descriptive statistics for severity, reading task, and speaking task scores associated with different postural conditions are presented in Table 2. When subjects sat on a chair with no arms, the majority had moderate or severe stuttering severity scores. Most subjects had mild stuttering severity scores associated with lying on a bed. The majority of subjects had mild or moderate stuttering severity scores when standing. Nearly equal numbers of subjects had mild or moderate stuttering severity scores associated with sitting on a chair with arms. When subjects stretched their neck muscles, most had a moderate stuttering severity score.
3.2. Comparisons of Severity, Reading, and Speaking Task Scores Associated with Different Body Positions. Comparisons of severity, reading task, and speaking task scores associated with different postural conditions are presented in Table 3. There were significant differences between stuttering severity, reading task, and speaking task scores associated with different postural conditions. Post hoc analysis revealed significant differences in stuttering severity, reading task, and speaking task scores when subjects were sitting on a chair with no arms compared to lying on a bed $(\mathrm{p}<0.05)$. Similarly, there were significant differences in these scores when subjects were sitting on a chair with no arms compared to a chair with arms $(\mathrm{p}<0.05)$.

\section{Discussion}

The current study aimed to evaluate stuttering severity for five different postural conditions using the SSI-4. The results 


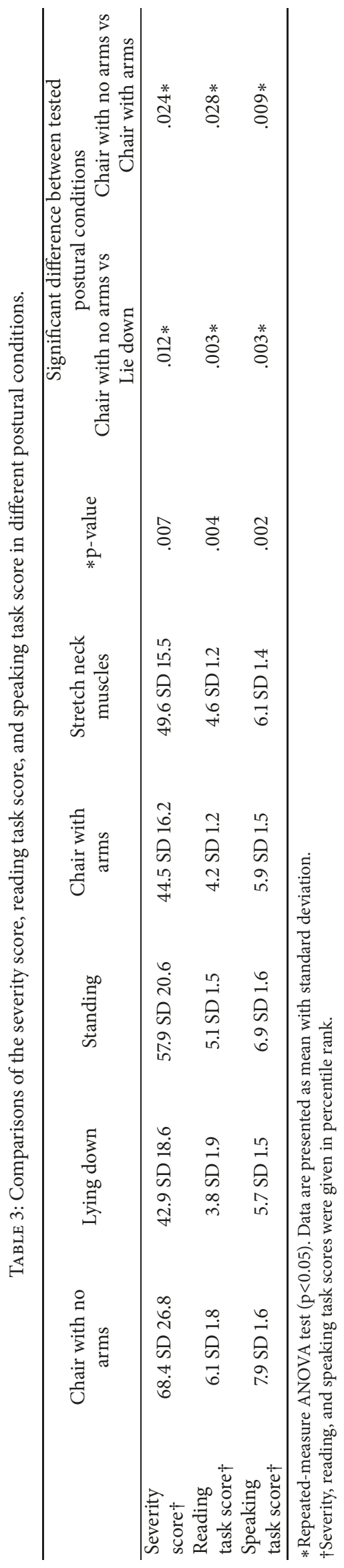


of the current study identified that lying down position was the most effective position for reducing stuttering severity. Most subjects in this position displayed mild stuttering severity. Sitting on a chair with arms was the second most effective position for reducing the severity of stuttering. In this position, half of the subjects displayed mild stuttering. None of the subjects showed severe or very severe stuttering while lying down or sitting on a chair with arms. Sitting on a chair with no arms or standing was the least effective position for reducing stuttering severity. Half of the subjects displayed severe or very severe stuttering while sitting on a chair with no arms. Moreover, while in a standing position, half of the subjects displayed moderate stuttering.

Compared to other postural conditions, lying down and sitting on a chair with arms had the lowest SSI-4 severity, reading task, and speaking task scores. Speech is considered to be the most complex motor activity, involving precise coordination of orofacial, laryngeal, and respiratory muscles. We suggest that the most effective body position (i.e., lying down and sitting on a chair with arms) supports maximal body relaxation, which might improve speech production. However, these relationships need to be investigated in more robust controlled studies in the future. It is further recommended to assess the impact of different body position on proprioceptive feedback during speech production to further validate these findings.

The muscles of the neck and jaw consist of densely populated muscle spindles [32], which can be activated by slight changes in the neck or body position. It was hypothesized that, similar to other motor functions, speech motor output depends on incoming proprioceptive and sensory information. Moreover, sensorimotor control plays a vital role in the production of speech [21]. Furthermore, Loucks et al. [33] indicate that PWS showed reduced proprioceptive function and poor oral motor task performance during specific target oriented jaw movements. Reduced proprioceptive measures have been associated with reduced ability to coordinate jaw movements with phonation, indicating the importance of this factor during articulatory discoordination often noticed in PWS [33]. The findings of the previous study indicate that people with severe stuttering who modify their movement strategy in order to improve movement accuracy may advocate that some of the noticed changes in the pattern of proprioceptive response could have resulted by movement strategy instead of sensory sensitivity [21]. Another study reported an association of increased movement accuracy and a slowing of movement speed, which indicates PWS become more fluent if they reduce their rate of speech. It is assumed that the impact of slowing speech on improved fluency could have been driven by an improved proprioceptive response [19]. Therefore, in the present study, we hypothesized that different body positions or postures may relax the muscles of the neck and upper extremities, which, in turn, may improve speech fluency in patients with developmental stuttering. During initial therapy sessions, using these body positions may help to correct speech motor output.

Based on our findings, we recommend that developmental stuttering therapy should begin with patients lying down during sessions since this position is the most comfortable for patients and reduces stuttering. While in this position, the patient's central nervous system may receive improved sensory inputs, leading to correct motor output. Once the level of stuttering decreases, patients can progressively experience different postural conditions during therapy sessions, such as sitting on a chair with arm support, standing, or sitting on a chair with no arm support.

The present study has several limitations. First, although our study only included subjects over 18 years old, we recognize that stuttering generally begins in childhood and more research is needed in this area. Second, although it is typical for the field, the small sample size $(n=24)$ of our study limits the validity of the results. Moreover, the use of mean scores may have masked the variations in some scores, for example, extreme high or low; however, due to the small sample size of our study, we cannot assess this. Finally, the validity of this study is limited given the lack of a control group.

\section{Conclusions}

Body postures or body segment positions that relax and facilitate the muscles of the neck and shoulders may potentially improve speech fluency in young adults with developmental stuttering. These findings may be of clinical significance; however, more longitudinal studies are needed to validate the results of this study.

\section{Abbreviations}

PWS: People who stutter

EBM: Evidence-based medicine

EBP: Evidence-based practice

SSI: Stuttering Severity Instrument

SLP: Speech-language pathologists.

\section{Data Availability}

All data generated or analyzed during this study are presented in the manuscript. Please contact the first author for access to data presented in this study.

\section{Disclosure}

The funders had no role in the study design, data collection, analysis, or interpretation, manuscript preparation, or decision to submit the manuscript for publication.

\section{Conflicts of Interest}

The authors declare that they have no conflicts of interest.

\section{Authors' Contributions}

Abdulaziz Almudhi, Hamayun Zafar, Shahnawaz Anwer, and Ahmad Alghadir significantly contributed to the concept and design of the study; Abdulaziz Almudhi and Shahnawaz Anwer drafted the manuscript; Shahnawaz 
Anwer, corresponding author, analysed and completed the manuscript; Hamayun Zafar, Abdulaziz Almudhi, and Ahmad Alghadir revised the manuscript critically. All the authors read and approved the final manuscript.

\section{Acknowledgments}

The authors are grateful to the Deanship of Scientific Research, King Saud University, for funding through Vice Deanship of Scientific Research Chairs. The authors would like to thank Mansour Bin-Dokhi for his enormous help, moral support, motivation, and kindness.

\section{References}

[1] J. Yaruss and R. W. Quesal, "Stuttering and the international classification of functioning, disability, and health (ICF): an update," Journal of Communication Disorders, vol. 37, no. 1, pp. 35-52, 2004.

[2] B. Guitar, Stuttering, An Intergrated Approach to Its Nature and Management, Lippincott Williams \& Wilkins, Baltimore, MD, USA, 2006.

[3] G. Andrews and M. Harris, The Syndrome of Stuttering, Clinics in Developmental Medicine, No. 17, Spastics Society Medical Education and Information Unit, in association with William Heinemann Medical Books, London, 1964.

[4] L. Ulliana and R. J. Ingham, "Behavioral and nonbehavioral variables in the measurement of stutterers' communication attitudes," Journal of Speech, Language, and Hearing Research, vol. 49, no. 1, pp. 83-93, 1984.

[5] H. Månsson, "Childhood stuttering," Journal of Fluency Disorders, vol. 25, no. 1, pp. 47-57, 2000.

[6] B. Guitar, Stuttering, An Integrated Approach to Its Nature and Treatmen, Lippincott Williams \& Wilkins, 2013.

[7] R. A. Martin, "A handbook on stuttering," Exceptional Children, vol. 36, no. 6, pp. 469-470, 1970.

[8] M. Blomgren, "Behavioral treatments for children and adults who stutter: a review," Psychology Research and Behavior Management, vol. 6, p. 9, 2013.

[9] D. Prins and R. J. Ingham, "Evidence-based treatment and stuttering-historical perspective," Journal of Speech, Language, and Hearing Research, vol. 52, no. 1, pp. 254-263, 2009.

[10] M. Prado-Velasco and C. Fernández-Peruchena, "An advanced concept of altered auditory feedback as a prosthesis-therapy for stuttering founded on a non speech etiologic paradigm," in Handbook of Research on Personal Autonomy Technologies and Disability Informatics, pp. 76-118, IGI Global, 2011.

[11] M. Lincoln, A. Packman, and M. Onslow, "Altered auditory feedback and the treatment of stuttering: a review," Journal of Fluency Disorders, vol. 31, no. 2, pp. 71-89, 2006.

[12] R. Ezrati-Vinacour and I. Levin, "The relationship between anxiety and stuttering: a multidimensional approach," Journal of Fluency Disorders, vol. 29, no. 2, pp. 135-148, 2004.

[13] A. Smith and C. Weber, "How stuttering develops: the multifactorial dynamic pathways theory," Journal of Speech, Language, and Hearing Research, vol. 60, no. 9, pp. 2483-2505, 2017.

[14] D. Ward, Stuttering and Cluttering: Frameworks for Understanding and Treatment, Psychology Press, 2nd edition, 2017.

[15] A. Almudhi, "Innovation of speech hand synchronization as a treatment in adults who stutter," Journal of Speech Pathology \& Therapy, vol. 1, no. 2, 2016.
[16] L. F. De Nil, "Stuttering: a neurophysiological perspective," in Stuttering Research and Practice: Bridging the Gap, N. BernsteinRatner and C. Healey, Eds., pp. 85-102, Lawrence Erlbaum, Mahwah, NJ, USA, 1999.

[17] K. Eggers, L. F. De Nil, and B. R. Van den Bergh, "The efficiency of attentional networks in children who stutter," Journal of Speech, Language, and Hearing Research, vol. 55, no. 3, pp. 946959, 2012.

[18] J. Sasisekaran and L. F. De Nil, "Phoneme monitoring in silent naming and perception in adults who stutter," Journal of Fluency Disorders, vol. 31, no. 4, pp. 284-302, 2006.

[19] L. Archibald and L. F. De Nil, "The relationship between stuttering severity and kinesthetic acuity for jaw movements in adults who stutter," Journal of Fluency Disorders, vol. 24, no. 1, pp. 25-42, 1999.

[20] L. F. De Nil and J. H. Abbs, "Kinaesthetic acuity of stutterers and non-stutterers for oral and non-oral movements," Brain, vol. 114, no. 5, pp. 2145-2158, 1991.

[21] L. De Nil, "Stuttering: imagining a solution to the riddle," Perspectives on Fluency and Fluency Disorders, vol. 19, no. 3, pp. 80-89, 2009.

[22] A. K. Namasivayam, P. van Lieshout, and L. De Nil, "Bite-block perturbation in people who stutter: Immediate compensatory and delayed adaptive processes," Journal of Communication Disorders, vol. 41, no. 4, pp. 372-394, 2008.

[23] C. Van Riper, The Nature of Stuttering, Prentice Hall, 1982.

[24] R. A. Schmidt, T. D. Lee, C. Winstein, G. Wulf, and H. N. Zelaznik, Motor Control and Learning: A Behavioral Emphasis, Human kinetics, 2018.

[25] M. D. McClean and S. M. Tasko, "Correlation of orofacial speeds with voice acoustic measures in the fluent speech of persons who stutter," Experimental Brain Research, vol. 159, no. 3, pp. 310-318, 2004.

[26] L. Max and V. L. Gracco, "Coordination of oral and laryngeal movements in the perceptually fluent speech of adults who stutter," Journal of Speech, Language, and Hearing Research, vol. 48, no. 3, pp. 524-542, 2005.

[27] O. Alizadehkhaiyat, M. M. Roebuck, A. T. Makki, and S. P. Frostick, "Postural alterations in patients with subacromial impingement syndrome," International Journal of Sports Physical Therapy, vol. 12, no. 7, pp. 1111-1120, 2017.

[28] H. Zafar, "Integrated jaw and neck function in man. Studies of mandibular and head-neck movements during jaw openingclosing tasks.", Swedish Dental Journal. Supplement, no. 143, pp. $1-41,2000$.

[29] S. Reilly, M. Onslow, A. Packman et al., "Natural history of stuttering to 4 years of age: a prospective community-based study," Pediatrics, vol. 132, no. 3, pp. 460-467, 2013.

[30] G. D. Riley and K. Bakker, Stuttering Severity Instrument: SSI-4: Pro-Ed, 2009.

[31] N. Tahmasebi, B. Shafie, H. Karimi, and M. Mazaheri, "A Persian-version of the stuttering severity instrument-version four (SSI-4): how the new additions to SSI-4 complement its stuttering severity score?" Journal of Communication Disorders, vol. 74, pp. 1-9, 2018.

[32] J.-X. Liu, L.-E. Thornell, and F. Pedrosa-Domellöf, "Muscle spindles in the deep muscles of the human neck: a morphological and immunocytochemical study," Journal of Histochemistry \& Cytochemistry, vol. 51, no. 2, pp. 175-186, 2003.

[33] T. M. Loucks, L. F. De Nil, and J. Sasisekaran, "Jaw-phonatory coordination in chronic developmental stuttering," Journal of Communication Disorders, vol. 40, no. 3, pp. 257-272, 2007. 


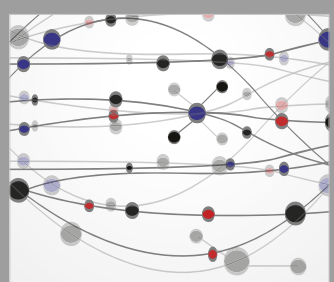

The Scientific World Journal
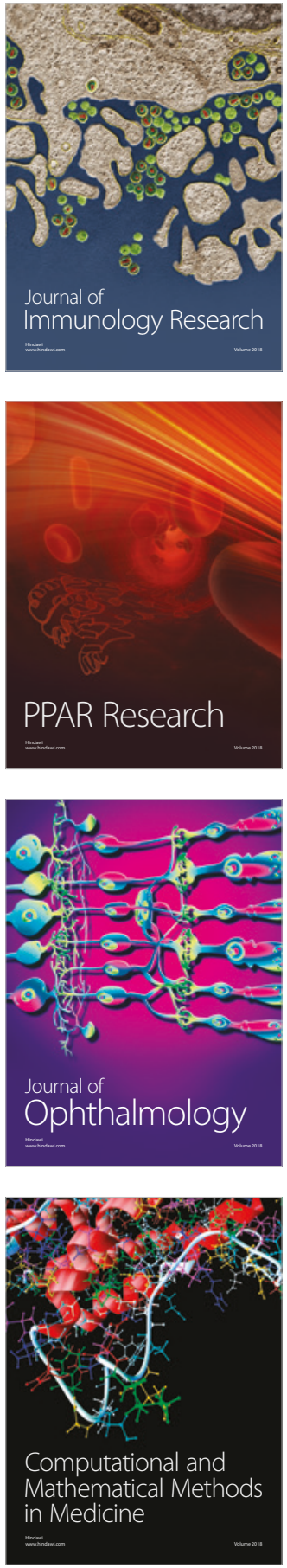

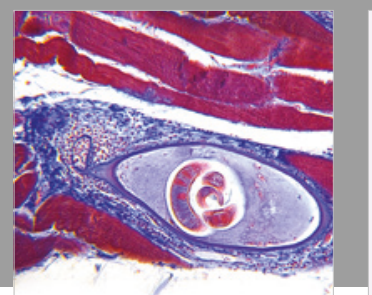

Gastroenterology Research and Practice

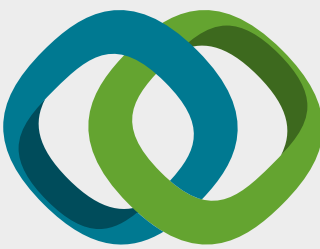

\section{Hindawi}

Submit your manuscripts at

www.hindawi.com
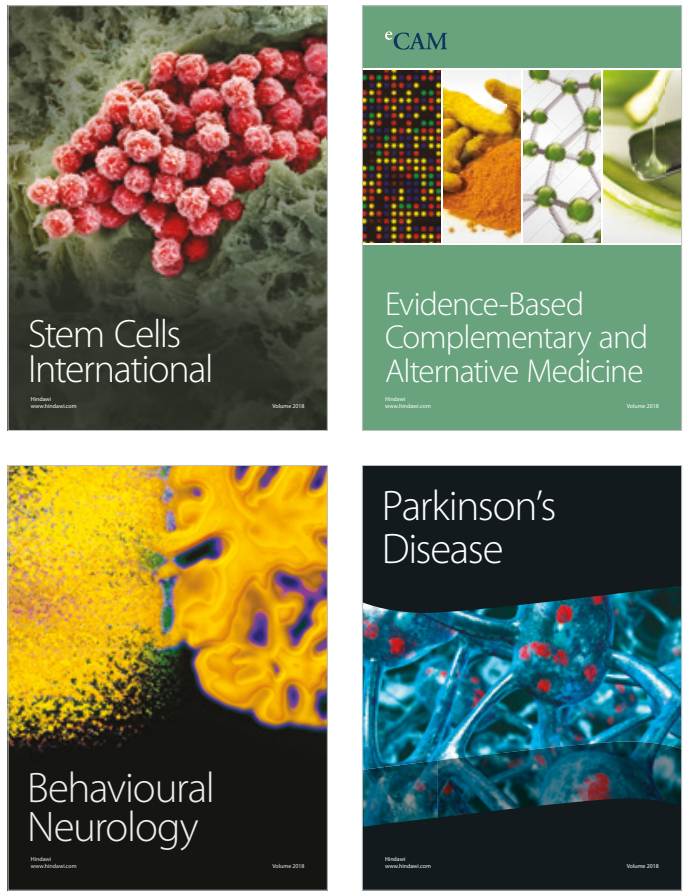

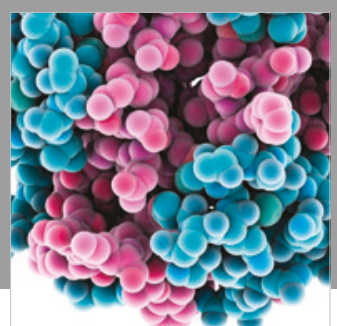

ournal of

Diabetes Research

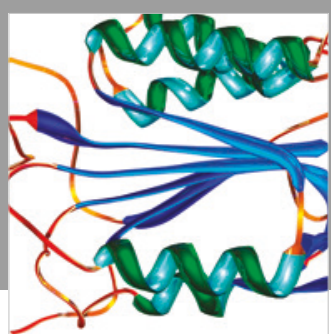

Disease Markers
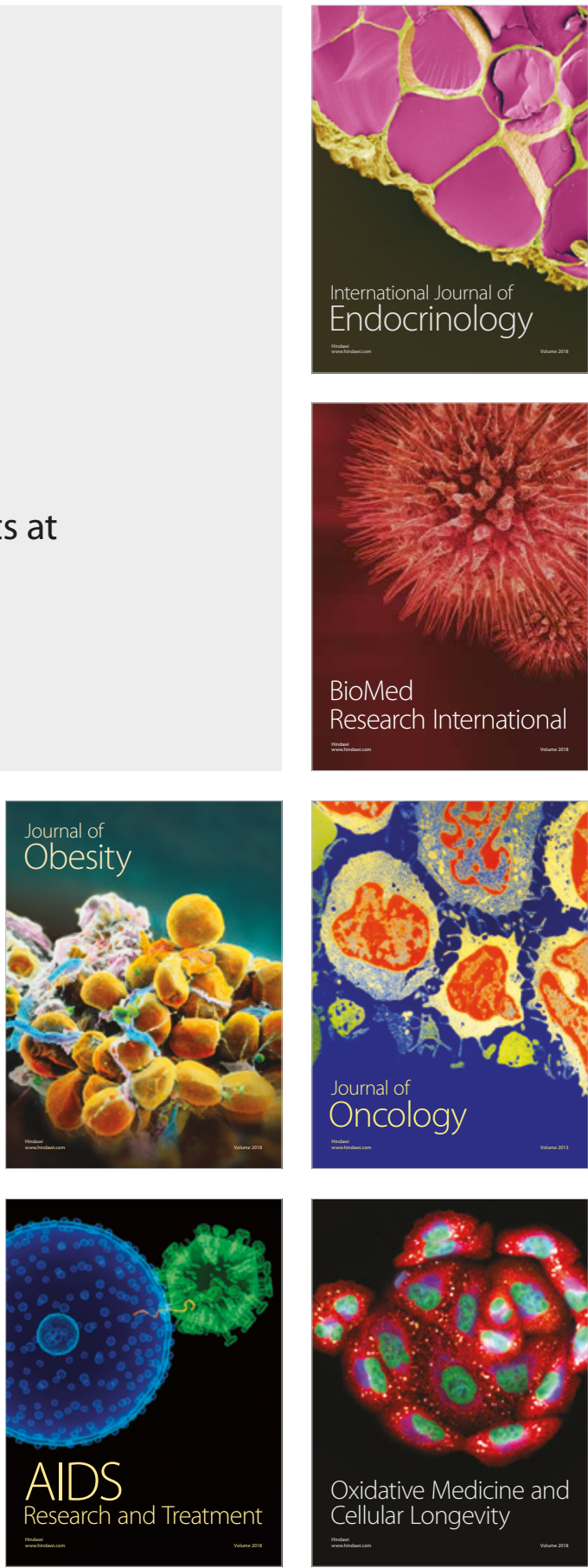